\title{
Glycemic Variability among Older Adults with Type 2 Diabetes
}

Chin Voon Tong*, Nurain Mohd Noor, Masni Mohamad, Shalena Nesaratnam and Zanariah Hussein

Endocrine Unit, Department of Medicine, Putrajaya Hospital, Malaysia

\begin{abstract}
Objective: The aim of this study was to evaluate Glycemic Variability (GV) among older adults with type 2 diabetes in a tertiary center (Putrajaya Hospital) using the Continuous Glucose Monitoring System (CGMS) and to compare the GV between patients with optimal versus suboptimal glycemic control.

Research designs and methods: A total of 138 patients $(69$ with $\mathrm{HbA} 1 \mathrm{c}<7 \%(53 \mathrm{mmol} / \mathrm{mol})$ and another 69 with $\mathrm{HbA} 1 \mathrm{c} \geq 7 \%(53 \mathrm{mmol} / \mathrm{mol})$ with type 2 diabetes age 65 and above were included in this study. All subjects underwent baseline clinical evaluation followed by monitoring using CGMS for six days. Data from CGMS was extracted to calculate GV using the Easy GV software available at www.easygv.co.uk.

Results: The patients with $\mathrm{HbA1c} \geq 7 \%(53 \mathrm{mmol} / \mathrm{l})$ had significantly longer duration of diabetes, higher use of insulin, more micro-vascular complications, higher systolic blood pressure, higher fasting blood glucose, total cholesterol and triglyceride levels. The Mean Amplitude Glycemic Excursions (MAGE), Continuous Overlapping Net Glycemic Action (CONGA, Standard Deviation (SD), M-value, Average Daily Risk Ratio (ADDR), Lability Index (LI), High Blood Glucose Index (HBGI), Mean of Daily Difference (MODD), Glycemic Risk Assessment in Diabetes Equation (GRADE) and Mean Absolute Glucose (MAG) were significantly higher in the group with $\mathrm{HbA} 1 \mathrm{c} \geq 7 \%$ $(53 \mathrm{mmol} / \mathrm{mol})$. The Low Blood Glucose Index (LBGI) [2.14(IQR 3.4) versus 2.11(2.6)] which represents risks of hypoglycemia was the only parameter which was not significantly different between both groups.

Conclusions: We present the glycemic variability parameters for older adults with type 2 diabetes. Among this population, the risk of hypoglycemia is similar between those with optimal HbA1c versus their counterparts. This underscores the importance of looking out for hypoglycemia in every older individual with type 2 diabetes.
\end{abstract}

Keywords: Type 2 diabetes; Glycemic variability; Older adults; Hypoglycemia; Continuous glucose monitoring system (CGMS); HbA1c; Microvascular complications; Macrovascular complications

\section{Introduction}

Diabetes in the older adults (defined as those aged 65 years and above) is an emerging epidemic associated with higher mortality, reduced functional status and increased risk of institutionalization [1]. In the local setting, the latest National Health and Morbidity Survey (NHMS 2015) reported that $17.5 \%$ of Malaysian adults aged 18 and above have diabetes. In the older population, above the age of 65 , the prevalence was between $37-39 \%$ [2]. Therefore a special focus on care of older persons with diabetes is pertinent to reduce the multitude of diabetic related complications and to improve the quality of life among the patients.

Both sustained hyperglycemia and acute glucose fluctuations contribute to the dysglycemia in diabetes and lead to diabetes complications through two main mechanisms; excessive protein glycation and oxidative stress [3]. Landmark studies have confirmed that post prandial hyperglycemia is an independent risk factor for macrovascular complications [4]. However, glycemic variability (GV) that includes both upward and downward acute glucose changes has been found to cause deleterious effects on endothelial function and oxidative stress which lead to development and progression of cardiovascular complications in diabetes as well. It was found that in type 2 diabetes, the urinary excretion of 8 -iso-PGF2 $\alpha$, which is a reliable marker of the activation of oxidative stress was highly, positively correlated with GV [5].

$\mathrm{HbAlc}$ which reflects average blood glucose over 2-3 months, is the commonest tool used to reflect glycemic control. However it cannot be used to assess postprandial hyperglycemia and fasting hyperglycemia separately and is unable to reflect short term glycemic changes or variability. Various other factors such as renal function, anemia and certain hemoglobinopathies also affect the validity of $\mathrm{HbAlc}$ results. Even patients who have $\mathrm{HbA} 1 \mathrm{c}$ levels below $7 \%(53 \mathrm{mmol} / \mathrm{mol})$ have been found to have GV and postprandial hyperglycemia [6].

Because of the limitations of $\mathrm{HbAlc}$, other tools are required to measure GV. However GV is a complex phenomenon with intra and inter-day components as well as minor and major fluctuations; thus several approaches have been developed to quantify it. By using data from the continuous glucose monitoring system (CGMS), various objective parameters can be assessed. This include the standard deviation (SD), M-Value, Mean Amplitude of Glucose Excursion (MAGE), average daily risk ratio (ADRR), Lability Index (LI), Low Blood Glucose Index (LBGI), High Blood Glucose Index (HBGI) continuous overlapping net glycemic action (CONGA), mean of daily differences (MODD), Glycemic Risk Assessment in Diabetes Equation (GRADE) and Mean absolute Glucose (MAG).

The GV among older adults with type 2 diabetes in a multiracial population like ours is not known. The aim of this study was to

*Corresponding author: Chin Voon Tong, Endocrine Unit, Department of Medicine, Putrajaya Hospital, Pusat Pentadbiran Kerajaan Persekutuan Presinct 7, 62250 Putrajaya, Malaysia, Tel: +60126026702; Fax: +0388889169; E-mail: tchinvoon@yahoo.com

Received February 16, 2016; Accepted February 26, 2016; Published February 29, 2016

Citation: Tong CV, Noor NM, Mohamad M, Nesaratnam S, Hussein Z (2016) Glycemic Variability among Older Adults with Type 2 Diabetes. J Diabetes Metab 7 652. doi:10.4172/2155-6156.1000652

Copyright: ( $) 2016$ Tong CV, et al. This is an open-access article distributed unde the terms of the Creative Commons Attribution License, which permits unrestricted use, distribution, and reproduction in any medium, provided the original author and source are credited. 
evaluate GV among older adults with type 2 diabetes attending the Diabetes Clinic in a tertiary center (Putrajaya Hospital) using the CGMS and to compare the GV between patients with optimal HbAlc of $<7 \%$ (53 $\mathrm{mmol} / \mathrm{mol}$ ) versus suboptimal glycemic control with $\mathrm{HbAlc} \geq 7 \%(53 \mathrm{mmol} / \mathrm{mol})$.

\section{Research Designs and Methods}

This was a single center cross sectional study performed over a 6-month period between August 2014 till February 2015. Consecutive patients attending the diabetes clinic in Putrajaya Hospital who fulfilled the inclusion criteria were offered to participate in the study [7]. The inclusion criteria were patients with type 2 diabetes (based on WHO criteria for diagnosis of diabetes) aged 65 years and above with a duration of diabetes of at least 5 years and treated with at least one glucose lowering medication (either oral hypoglycemic agents or insulin).

The exclusion criteria were subjects with secondary diabetes, type 1 diabetes, those who are taking medications that may impair glucose metabolism (example steroids) and subjects with recent addition or omission of glucose lowering medications in the past 3 months. Sample size was calculated using Dupont et al. [8,9] sample size calculations formulae.

The study population was divided into two groups of patients with type 2 diabetes age 65 years and above. The first group consisted of 69 patients with $\mathrm{HbA} 1 \mathrm{c}<7 \%(53 \mathrm{mmol} / \mathrm{mol})$ and the second group another 69 patients with $\mathrm{HbA1c} \geq 7 \%(53 \mathrm{mmol} / \mathrm{mol})$. All subjects underwent baseline clinical evaluations followed by monitoring using CGMS for six days. During evaluation by CGMS, each patient kept an activity log. During Visit 1, informed consent was obtained. Baseline history and clinical assessment were carried out. Information collected included age, duration of diabetes, family history of diabetes, presence of comorbidities, glucose lowering medications, anti-hypertensives and lipid lowering medications used as well as complications of diabetes. Anthropometric measurements included weight, height, waist and hip circumference. Weight and height were taken using a standardized SECA measuring station and column scale. Waist circumference was measured midway between the highest point of the iliac crest and the bottom of the ribcage. Hip circumference was measured around the widest portion of the buttock. Body Mass Index (BMI) in $\mathrm{kg} / \mathrm{m}^{2}$ and Waist Hip Ratio (WHR) were calculated. Blood pressure was taken by an automated blood pressure machine (Omron). Two measurements were taken and the mean blood pressure reading was then recorded. Baseline biochemical assessment included fasting venous glucose, fasting lipid profile, HbAlc, serum creatinine, e-GFR (Glomerular Filtration Rate) and urine protein. These blood investigations were performed on Visit 1 or within a month prior to Visit 1 .

CGMS (Medtronic Minimed) monitoring was performed over 6 days, using the Enlite sensor from Medtronic. Subjects were encouraged to continue their regular daily activities, diet and medications. Minimal care of CGMS site was required and this was explained to patients. Each subject was provided with a standardized glucometer (Free Style Freedom Lite) and instructed to keep an activity log which included pre-meals and pre-bed capillary blood glucose measurements, relevant activities which included meal time and contents, physical activities, timing of glucose lowering medications and hypoglycemic events if any. Following completion of 6 days, CGMS was removed and data downloaded and analyzed. GV parameters were calculated using Easy GV software which is available at www.easygv.co.uk.
Statistical analysis was performed with SPSS (version 21) statistics software. The statistical tests used were Chi-square and Fischer's exact tests for the categorical data. Meanwhile for numerical data, independent t-test was used for parametric data and Mann-Whitney test for non-parametric data. Spearman's correlation was used to evaluate the associations between $\mathrm{HbAlc}$ and MAGE. A multivariate regression analysis was used to determine confounding factors for MAGE. $\mathrm{P}<0.05$ was considered to be statistically significant.

\section{Results}

The patients with $\mathrm{HbAlc} \geq 7 \%$ ( $53 \mathrm{mmol} / \mathrm{mol}$ ) had longer duration of diabetes (Median=14, IQR 10 years) compared to those who had $\mathrm{HbAlc}<7 \%$ ( $53 \mathrm{mmol} / \mathrm{mol}$ ) (Median=10, IQR 10years). The group with $\mathrm{HbAlc} \geq 7 \%(53 \mathrm{mmol} / \mathrm{mol})$ comprised more insulin users, higher microvascular complications and higher systolic blood pressure. Baseline investigations showed that the patients in this group had higher fasting blood glucose, total cholesterol and triglyceride levels. Both groups had similar number of blood glucose measurements from the CGM. Those with $\mathrm{HbA} 1 \mathrm{c}<7 \%$ ( $53 \mathrm{mmol} / \mathrm{mol}$ ) had a median of 2020 (IQR 67) readings while those with $\mathrm{HbAlc} \geq 7 \%$ (53 mmol/ $\mathrm{mol}$ ) had 2026 (IQR 62) readings $(\mathrm{p}<0.226)$. Both groups also had correlation numbers for CGM of $>0.79$ which is regarded as the level above which is considered clinically acceptable and optimal correlation. The correlation number (generated from CGM data) is derived from the comparison between the blood glucose readings from the CGM compared to finger prick blood glucose readings. The baseline characteristics of all the subjects are summarized in Table 1.

The patients with $\mathrm{HbAlc} \geq 7 \%$ (53 $\mathrm{mmol} / \mathrm{mol}$ ) had significantly higher GV in all parameters except one. The MAGE, CONGA, SD, M-value, ADDR, LI, HBGI, MODD, GRADE and MAG were significantly higher in the group with $\mathrm{HbAlc} \geq 7 \%(53 \mathrm{mmol} / \mathrm{mol})$. The LBGI was the only parameter which was not significantly different between both groups. The differences in the GV parameters were shown in Table 2.

A Spearman's correlation coefficient was computed to assess the relationship between $\mathrm{HbAlc}$ and MAGE. There was a positive but significant correlation between $\mathrm{HbAl} c$ and MAGE with $\mathrm{r}=0.37$, $\mathrm{p}$ of $<0.001$ (Table 3 and Figure 1). We also found that our patients with microvascular complications had significantly higher MAGE $(5.17 \mathrm{mmol} / \mathrm{l} \pm 1.678)$ compared to those who did not $(4.55 \mathrm{mmol} / \mathrm{l}( \pm 1.876)$; $\mathrm{p}$ value 0.049 . MAGE between those with and without macrovascular complications were however not significantly different.

\section{Discussion}

The two groups of older adults with Type 2 diabetes studied were similar in terms of age, gender and represented the ethnic diversity in Malaysia. The group with $\mathrm{HbAlc} \geq 7 \%(53 \mathrm{mmol} / \mathrm{mol})$, had longer duration of disease. Co-morbidities such as hypertension and dyslipidemia and the associated medications for their treatment were not different between the groups. Oral glucose lowering medications used were not significantly different between the groups but insulin use was higher in the group with $\mathrm{HbA1c} \geq 7 \%$ (53 $\mathrm{mmol} / \mathrm{mol})$. $(68.1 \%$ versus $40.6 \%, \mathrm{p}=0.001$ ). Total cholesterol, triglyceride and systolic blood pressure were also noted to be significantly higher in the group with $\geq 7 \%(53 \mathrm{mmol} / \mathrm{mol})$. In essence, the group with poorer glycemic control also seemed to have higher cardiovascular risks.

Unexpectedly, although the group with $\mathrm{HbAlc} \geq 7 \%(53 \mathrm{mmol} /$ mol) had higher composite of microvascular complications $(75.4 \%)$ compared to $54.6 \%$ in the group with $\mathrm{HbAlc}<7 \%(53 \mathrm{mmol} / \mathrm{mol})$ 
Citation: Tong CV, Noor NM, Mohamad M, Nesaratnam S, Hussein Z (2016) Glycemic Variability among Older Adults with Type 2 Diabetes. J Diabetes Metab 7: 652. doi:10.4172/2155-6156.1000652

Page 3 of 5

\begin{tabular}{|c|c|c|c|}
\hline & $\begin{array}{c}\text { HbA1c< }<\% \\
(53 \mathrm{mmol} / \mathrm{mol})\end{array}$ & $\begin{array}{c}\mathrm{HbA} 1 \mathrm{c} \geq 7 \% \quad(53 \\
\mathrm{mmol} / \mathrm{mol})\end{array}$ & $P$ value \\
\hline $\mathrm{N}$ & 69 & 69 & \\
\hline Age* $^{*}$ & 69 (IQR 6) & 68 (IQR 6) & 0.05 \\
\hline \multicolumn{4}{|l|}{ Gender } \\
\hline Female & $29(42 \%)$ & $28(40.6 \%)$ & 0.865 \\
\hline Male & $40(58 \%)$ & $41(59.4 \%)$ & \\
\hline Duration (years) * & 10 (IQR 10) & 14 (IQR 10) & 0.001 \\
\hline Family history & $51(73.9 \%)$ & $44(63.8 \%)$ & 0.198 \\
\hline \multicolumn{4}{|l|}{ Race } \\
\hline Malay & 35 & 39 & 0.57 \\
\hline Chinese & 19 & 14 & \\
\hline Indian & 14 & 13 & \\
\hline Others & 1 & 3 & \\
\hline \multicolumn{4}{|l|}{$\begin{array}{l}\text { Glucose Lowering } \\
\text { Medications }\end{array}$} \\
\hline Oral Hypoglycemic Agents & $58(84.1 \%)$ & $55(79.7 \%)$ & 0.507 \\
\hline Sulfonylurea & $28(40.6 \%)$ & $28(40.6 \%)$ & 1.00 \\
\hline Metformin & $52(75.4 \%)$ & $51(73.9 \%)$ & 0.845 \\
\hline DPP4 inhibitors & $12(17.4 \%)$ & $11(15.9 \%)$ & 0.819 \\
\hline Insulin & $28(40.6 \%)$ & $47(68.1 \%)$ & 0.001 \\
\hline Human insulin & $25(36.2 \%)$ & $41(59.4 \%)$ & 0.006 \\
\hline Insulin Analog & $5(7.2 \%)$ & $12(17.4 \%)$ & 0.007 \\
\hline \multicolumn{4}{|l|}{ Co-morbidities } \\
\hline Hypertension & $60(87 \%)$ & $65(94.2 \%)$ & 0.145 \\
\hline Dyslipidemia & $66(95.7 \%)$ & $67(97.1 \%)$ & 1.00 \\
\hline Others & $21(30.4 \%)$ & $12(17.4 \%)$ & 0.072 \\
\hline \multicolumn{4}{|l|}{ Medications } \\
\hline Anti hypertensives & $59(85.5 \%)$ & $65(94.2 \%)$ & 0.091 \\
\hline ACE inhibitor & $46(66.7 \%)$ & $53(76.8 \%)$ & 0.186 \\
\hline Beta blocker & $22(31.9 \%)$ & $31(44.9 \%)$ & 0.115 \\
\hline Calcium Channel Blocker & $33(47.8 \%)$ & $41(59.4 \%)$ & 0.172 \\
\hline Diuretics & $13(18.8 \%)$ & $21(30.4 \%)$ & 0.114 \\
\hline Alpha blockers & $7(10.1 \%)$ & $6(8.7 \%)$ & 0.771 \\
\hline Lipid lowering agents & $65(94.2 \%)$ & $67(97.1 \%)$ & 0.681 \\
\hline Statin & $64(92.8 \%)$ & $65(94.2 \%)$ & 1.00 \\
\hline Fibrates & $1(1.4 \%)$ & $5(7.2 \%)$ & 0.208 \\
\hline Ezetimibe & $2(2.9 \%)$ & $1(1.4 \%)$ & 1.00 \\
\hline \multicolumn{4}{|l|}{ Complications } \\
\hline Microvascular & $37(53.6 \%)$ & $52(75.4 \%)$ & 0.008 \\
\hline Retinopathy & $20(29 \%)$ & $27(39.1 \%)$ & 0.209 \\
\hline Neuropathy & $18(26.1 \%)$ & $36(52.2 \%)$ & 0.002 \\
\hline Nephropathy & $22(31.9 \%)$ & $27(39.1 \%)$ & 0.374 \\
\hline Macrovascular & $24(34.8 \%)$ & $27(39.1 \%)$ & 0.597 \\
\hline Ischemic Heart Disease & $22(31.9 \%)$ & $24(34.8 \%)$ & 0.718 \\
\hline Cerebrovascular Accident & $5(7.2 \%)$ & $6(8.7 \%)$ & 0.753 \\
\hline \multicolumn{4}{|l|}{ Examination } \\
\hline Systolic BP (mmHg) & $141( \pm 19.1)$ & $149(( \pm 22.5)$ & 0.033 \\
\hline Diastolic BP (mmHg) & $76(( \pm 10.2)$ & $76(( \pm 12.8)$ & 0.769 \\
\hline Body Mass Index* & 26.8 (IQR 4.61) & $27.2($ IQR 6.20$)$ & 0.751 \\
\hline Waist Hip Ratio* & 0.92(IQR 0.100) & 0.95 (IQR 0.008) & 0.061 \\
\hline \multicolumn{4}{|l|}{ Investigations } \\
\hline $\begin{array}{l}\text { Fasting Blood Sugar* } \\
\qquad(\mathrm{mmol} / \mathrm{l})\end{array}$ & 5.9 (IQR 1.60) & 7.60(IQR 3.30) & $<0.001$ \\
\hline $\mathrm{HbA}_{1} \mathrm{c}^{*}(\%)[\mathrm{mmol} / \mathrm{mol}]$ & $\begin{array}{c}6.6[49](I Q R \\
0.65)\end{array}$ & $\begin{array}{c}8.5[69](I Q R \\
1.80)\end{array}$ & $<0.001$ \\
\hline Creatinine* (umol) & 95 (IQR 54.5) & 102 (IQR 53.5) & 0.717 \\
\hline eGFR* & 66 (IQR 27.25) & 63.0 (IQR 24.64) & 0.498 \\
\hline
\end{tabular}

\begin{tabular}{|c|c|c|c|}
\hline Total Cholesterol(mmol/l) & $4.22( \pm 0.911)$ & $4.23( \pm 1.149)$ & 0.001 \\
\hline $\operatorname{LDL}(\mathrm{mmol} / \mathrm{l})$ & $2.39( \pm 0.804)$ & $2.38( \pm 0.889)$ & 0.805 \\
\hline $\mathrm{HDL}(\mathrm{mmol} / \mathrm{l})$ & $1.28( \pm 0.364)$ & $1.18( \pm 0.239)$ & 0.058 \\
\hline $\mathrm{Tg}^{*}(\mathrm{mmol} / \mathrm{l})$ & $1.2($ IQR 0.70$)$ & $1.5 \mathrm{IQR}(1.1)$ & 0.018 \\
\hline \multicolumn{4}{|c|}{ CGM related values } \\
\hline Number of readings* & 2020 (IQR 67) & 2026(IQR 62) & 0.226 \\
\hline Correlation number* & 0.90 (IQR 0.10$)$ & 0.93 (IQR 0.09) & 0.191 \\
\hline
\end{tabular}

Note: *data expressed in median (IQR)

Abbreviations: LDL: Low Density Lipid; HDL: High Density Lipid, Tg: Triglyceride; CGM: Continuous Glucose Monitoring

Table 1: Baseline characteristics.

\begin{tabular}{|c|c|c|c|}
\hline Parameters & $\begin{array}{c}\mathrm{HbA1c}<7 \% \\
(53 \mathrm{mmol} / \mathrm{mol})\end{array}$ & $\begin{array}{c}\mathrm{HbA1c} \geq 7 \% \\
(53 \mathrm{mmol} / \mathrm{mol})\end{array}$ & $P$ value \\
\hline CONGA* & 6.49 (IQR 1.29) & 8.10 (IQR 2.23) & $<0.001$ \\
\hline SD & $2.18( \pm 0.910)$ & $3.01( \pm 0.854)$ & $<0.001$ \\
\hline M-VALUE* & 4.13 (IQR 6.04) & 10.51 (IQR 10.30) & $<0.001$ \\
\hline MAGE & $4.45( \pm 1.801)$ & $5.45( \pm 1.600)$ & 0.001 \\
\hline ADDR & $15.30( \pm 8.587)$ & $27.69( \pm 12.068)$ & $<0.001$ \\
\hline $\mathrm{LI}^{*}$ & 2.19 (IQR 1.651) & 3.17 (IQR 2.235) & 0.001 \\
\hline LBGI $^{*}$ & 2.11 (IQR 2.61) & 2.14 (IQR 3.43) & 0.743 \\
\hline $\mathrm{HBGI}^{*}$ & 3.85 (IQR 4.89) & 9.28 (IQR 6.49) & $<0.001$ \\
\hline MODD & $2.29( \pm 0.974)$ & $3.11( \pm 0.942)$ & $<0.001$ \\
\hline GRADE* $^{*}$ & 2.89 (IQR 3.32) & 7.52 (IQR 6.25) & $<0.001$ \\
\hline MAG * & 1.40 (IQR 0.66) & 1.65 (IQR 0.69) & $<0.001$ \\
\hline
\end{tabular}

Note: *data expressed in median (IQR)

Abbreviations: CONGA: Continuous Overlapping Net Glycemic Action; SD: Standard Deviation; MAGE: Mean Amplitude of Glucose Excursion; ADDR: Average daily risk ratio; LI: Lability Index; LBGI: Low Blood Glucose Index; HBGI High Blood Glucose Index; MODD: Mean of Daily Differences; GRADE: Glycemic Risk Assessment in Diabetes Equation; MAG: Mean absolute Glucose

Table 2: Comparison of GV parameters between 2 groups.

\begin{tabular}{|c|c|c|c|}
\hline Variable & Mean $( \pm \mathrm{SD})$ & $\mathrm{r}$ & P value \\
\hline HbA1c & $7.7(61 \mathrm{mmol} / \mathrm{mol})( \pm 1.67)$ & 0.37 & $\mathrm{P}<0.001$ \\
\hline MAGE & $5.0( \pm 1.77)$ & & \\
\hline
\end{tabular}

Abbreviation: MAGE: Mean Amplitude of Glucose Excursion

Table 3: Spearman's correlation coefficients $(r)$ of HbA1c and MAGE $(n=138)$.

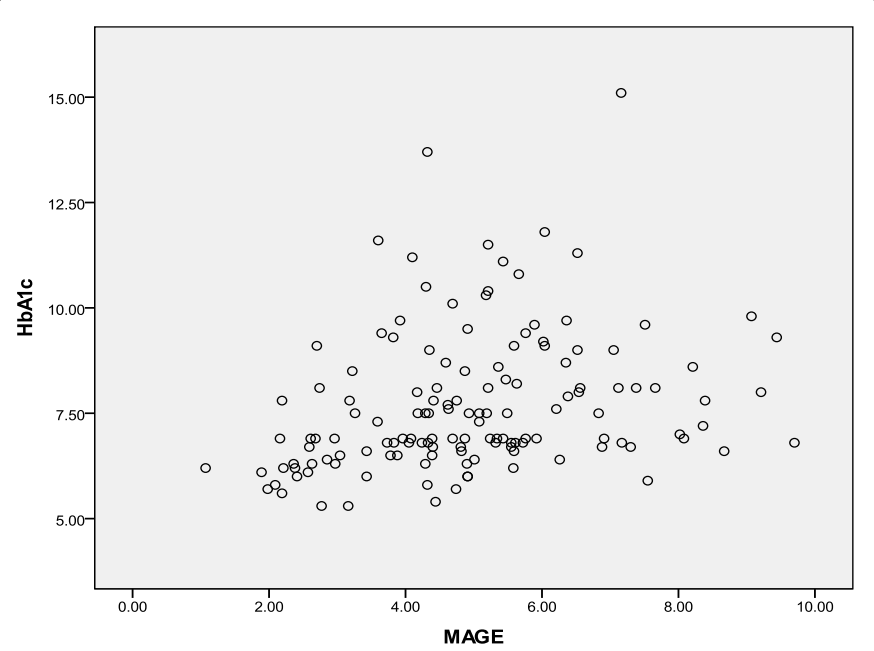

Figure 1: Correlation between $\mathrm{HbA} 1 \mathrm{c}$ and MAGE. 
Citation: Tong CV, Noor NM, Mohamad M, Nesaratnam S, Hussein Z (2016) Glycemic Variability among Older Adults with Type 2 Diabetes. J Diabetes Metab 7: 652. doi:10.4172/2155-6156.1000652

Page 4 of 5

\begin{tabular}{|c|c|c|c|}
\hline Authors & Characteristics of subjects & HbA1c/ blood glucose & MAGE reported \\
\hline \multirow{2}{*}{ This study } & \multirow{2}{*}{ Malaysian Type 2 diabetes age 65 years and above } & $\begin{array}{l}\mathrm{HbA} 1 \mathrm{c}<7 \% \\
(\mathrm{n}=69)\end{array}$ & $4.45 \mathrm{mmol} / \mathrm{l}( \pm 1.80)$ \\
\hline & & $\begin{array}{l}\mathrm{HbA} 1 \geq 7 \% \\
(\mathrm{n}=69)\end{array}$ & $5.45 \mathrm{mmol} / \mathrm{l}( \pm 1.60)$ \\
\hline Hill et al. [7] & Normal non diabetic Asians & $\begin{array}{l}\text { FBS }<6.7 \mathrm{mmol} / \mathrm{l} \\
(\mathrm{n}=7)\end{array}$ & $1.3(0.7)$ \\
\hline Jian Zhou et al. [15] & Normal non diabetic Chinese patients & $\begin{array}{l}\text { Normal OGTT } \\
(n=434)\end{array}$ & $1.73 \mathrm{mmol} / \mathrm{l}(1.08)$ \\
\hline \multirow{2}{*}{ Fang et al. [10] } & \multirow{2}{*}{ Elderly (>60 years old) Chinese male patients with Type 2 diabetes } & $\begin{array}{l}\mathrm{HbA} 1 \mathrm{c}<7 \% \\
(\mathrm{n}=153)\end{array}$ & $3.48 \mathrm{mmol} / \mathrm{l} \pm 1.46$ \\
\hline & & $\begin{array}{l}\mathrm{HbA} 1 \geq 7 \% \\
(\mathrm{n}=138)\end{array}$ & $4.33 \mathrm{mmol} / \mathrm{l} \pm 1.67$ \\
\hline \multirow{2}{*}{ Xu et al. [14] } & $\begin{array}{l}\text { Type } 2 \text { diabetic patients with well controlled diabetes without diabetic neuropathy } \\
\text { (Chinese population) }\end{array}$ & $\begin{array}{l}\text { Mean } \mathrm{HbA} 1 \mathrm{c} 6.4 \% \pm 0.4 \\
(\mathrm{n}=45)\end{array}$ & $4.5 \mathrm{mmol} / \mathrm{l} \pm 0.9$ \\
\hline & $\begin{array}{l}\text { Type } 2 \text { diabetic patients with well controlled diabetes with diabetic neuropathy } \\
\text { (Chinese population) }\end{array}$ & $\begin{array}{l}\text { Mean } \mathrm{HbA} 1 \mathrm{c} 6.5 \% \pm 0.4 \\
(\mathrm{n}=45)\end{array}$ & $5.8 \mathrm{mmol} / \mathrm{l} \pm 1.6$ \\
\hline Gong et al. [13] & $\begin{array}{l}\text { Chinese patients admitted for acute myocardial infarct, irrespective of diabetes } \\
\text { status }\end{array}$ & $\begin{array}{l}\text { Hba1c } \geq 6.5 \% \text { with mean of } 7.68 \\
\pm 1.13\end{array}$ & $4.10 \mathrm{mmol} / \mathrm{l} \pm 1.34$ \\
\hline \multirow{2}{*}{ Engler et al. [11] } & \multirow{2}{*}{ German patients with Type 2 diabetes } & $\begin{array}{l}\mathrm{HbA} 1 \mathrm{c}<7 \% \\
(\mathrm{n}=63)\end{array}$ & $2.6 \mathrm{mmol} / \mathrm{l} \pm 1.1$ \\
\hline & & $\begin{array}{l}\operatorname{HbA} 1 \mathrm{c} \geq 7 \% \\
(\mathrm{n}=45)\end{array}$ & $4.8 \mathrm{mmol} / \mathrm{l} \pm 2.1$ \\
\hline Gribovschi et al. [16] & Romanian patients with type 2 diabetes & Mean $\mathrm{HbA} 1 \mathrm{c} 8.42 \%( \pm 1.99)$ & $3.41 \mathrm{mmol} / \mathrm{l}( \pm 1.98)$ \\
\hline
\end{tabular}

Table 4: Comparison of MAGE with other studies.

\begin{tabular}{|c|c|c|}
\hline Factors & P value & Confidence interval 95\% \\
\hline Sulphonylurea use & $<0.001$ & $0.869,1.831$ \\
\hline Human insulin use & $<0.001$ & $0.695,1.969$ \\
\hline Analog insulin use & 0.005 & $0.399,2.163$ \\
\hline
\end{tabular}

Table 5: Multivariate regression analysis for confounding factors of MAGE.

(p 0.008), there were no differences between the groups in terms of macrovascular complications. One possible explanation is that cardiac ischaemia may be silent and undetected in elderly patients with diabetes and the information obtained regarding macrovascular complications was based on history with no formal assessment done.

The MAGE, which is one of the commonest parameters used to quantify glycemic variability, estimates the major fluctuations in glucose profiles. It is obtained by measuring the arithmetic mean of the differences between consecutive peaks and nadirs provided that the differences are greater than one SD of the mean glucose value [4]. MAGE is generally regarded as the "gold standard" parameter to describe glycemic variability. The MAGE in our group of patients with $\mathrm{HbA} 1 \mathrm{c} \geq 7 \%(53 \mathrm{mmol} / \mathrm{mol})$ was $5.45 \mathrm{mmol} / \mathrm{l}( \pm 1.600)$; significantly higher than the $4.45 \mathrm{mmol} / \mathrm{l}( \pm 1.801)$ in the group with $\mathrm{HbAlc}<7 \%$ $(53 \mathrm{mmol} / \mathrm{mol})$. In comparison with MAGE reported in other studies (Table 4), except for one study [7,10-15], our patients seem to have more glycemic variability; even those with good glycemic control from $\mathrm{HbAlc}$ point of view. Feng et al. [13] reported a similar MAGE (among Chinese population) with ours. This reflects the fact that many other factors such as types of food and therapies affect glycemic variability. Further analysis showed that among our patients, there is a significant correlation between HbAlc and MAGE; a focus in glycemic variability seems important, especially in those with higher HbAlc. A further multivariate regression analysis of factors that may affect MAGE such as duration of diabetes, fasting blood sugar, HbAlc, uses of metformin, sulphonylurea, DPP4 inhibitor, human insulin, analog and beta blocker as well as eGFR, presence of micro and macrovascular complications was performed and we found that the most significant factors confounding MAGE are the use of sulphonylurea, human insulin and analog (Table 5). This suggests that in patients who have high MAGE, the use of these agents may need to be reviewed.

The LBGI and the HBGI split the overall glucose variation into two independent sections related to excursions into hypo- and hyperglycemia, and at the same time equalize the amplitude of these excursions with respect to the risk they carry [16-19]. The LBGI and HBGI formulae are implemented by converting glucose values into risk scores [7]. Larger values of LBGI and HBGI indicate higher risk for hypo and hyperglycemia respectively. In repeated studies it has been established that four risk categories of the LBGI can be identified: minimal risk for hypoglycaemia: $\mathrm{LBGI} \leq 1.1$, low risk: $1.1<\mathrm{LBGI} \leq$ 2.5, moderate risk: $2.5<\mathrm{LBGI} \leq 5$; and high risk: LBGI $>5$ [16]. Interestingly, in our study, both groups of patients did not differ in terms of LBGI but the HBGI was three times higher in the group with $\mathrm{HbAlc} \geq 7 \%$ (53 mmol/mol). This highlights the importance of focusing in hypoglycemia in all elderly patients regardless of HbAlc.

$\mathrm{SD}$ is calculated from patient's blood glucose readings and shows how much variation or dispersion from the average blood glucose level (mean). It is appropriate for assessing intraday glycemic variability. The CONGA is similar to the SD. The determination is based on the assessment of the differences between glucose values measured at regular time intervals, then on the calculation of SD of these differences. It assesses the intraday GV [4]. The M-value is a logarithmic transformation of the deviation of glycaemia from an arbitrarily assigned "ideal" glucose value. It is calculated on each glucose value using a formula then divided by total values to derive at a mean. It attempts to provide, in a single numerical value, an expression of both the mean glucose value and the effect of glucose swings [4]. Most parameters such as SD are more sensitive to hyperglycemic surges than to hypoglycemic changes. This is due to the asymmetry of 
Citation: Tong CV, Noor NM, Mohamad M, Nesaratnam S, Hussein Z (2016) Glycemic Variability among Older Adults with Type 2 Diabetes. J Diabetes Metab 7: 652. doi:10.4172/2155-6156.1000652

Page 5 of 5

blood glucose scale; which can be corrected numerically. The ADRR which is calculated by transforming each glucose value using a formula and then attributing a risk value to the transformed point is a measure of glucose variability which was designed to be equally sensitive to hypoglycemia and hyperglycemia levels of glucose [17]. A lability value is calculated by processing three glucose readings and then moves on to the next three values and so on. The LI is the mean of these values [7]. LI measures how labile or brittle a patient's diabetes is. The MODD formula is calculated as the average of the difference between values on different days but at the same time [4]. It provides an assessment of interday GV. The GRADE score of glucose profiles summarizes the degree of risk associated with a glucose profile. The GRADE formula converts glucose values to a risk score, calculates the median and provides the risk attributable to hypoglycemia and hyperglycemia [7]. Normal GRADE value has been reported as $<5$ [18]. MAG calculates the sum of the differences between successive glucose values divided by the total time measured in hours.

Despite the seemingly complex explanation/formula of each GV parameter, our study showed a very simple conclusion which is - all the parameters calculated consistently showed higher GV among our group of patients with $\mathrm{HbAlc} \geq 7 \%(53 \mathrm{mmol} / \mathrm{mol})$ except for LBGI. However the fact that even those with $\mathrm{HbAlc}<7 \%(53 \mathrm{mmol} / \mathrm{mol})$ showed some degree of GV indicates that glycemic control should be evaluated beyond $\mathrm{HbAlc}$ alone. CGMS is emerging as a valuable tool to aid in glycemic management. Its pictorial presentation allows clinicians to identify glycemic excursions and individualize therapy. However, the GV parameters calculated in our studies allow a more objective assessment of GV and can be used to monitor progress. The MAGE in our opinion is the most useful parameter. It is more widely used and therefore comparisons with values from other studies offer a better light to GV among our population of patients. The concept of care manager who plays the link between patients and healthcare providers has been shown to contribute positive impact towards patients' knowledge and self-management skills [19]. Sharing and explaining the GV parameters obtained with patients via their care managers could empower them further and lead to greater self sufficiency.

Limitations of this study are lack of data on smoking history and the possible underestimation of macrovascular complications as history of these complications are obtained from patients and clinical notes entered by physician with no formal assessment like angiography. The strength of this study is that it is the first done locally to assess glycemic variability among older diabetics.

\section{Conclusion}

We present the glycemic variability parameters for older adults with type 2 diabetes. Among this population, the risk of hypoglycemia is similar between those with optimal HbAlc versus their counterparts.

\section{Acknowledgement}

This study received funding from National Institute of Health $(\mathrm{NIH})$ of Malaysia. The project/grant number is MRG-MOH-2014-23. We have no potential conflicts of interest to declare.

\section{References}

1. Brown AF, Mangione CM, Sarkisian CA, Geffen D, Saliba D, et al. (2003) Guidelines for improving the care of the older person with diabetes mellitus. $J$ Am Geriatr Soc 51: S265-S280.

2. Aris T, Yusof MFM, Abd Ghani AA (2016) National Health and Morbidity Survey 2015 Report Volume 2: Non-communicable Diseases, Risk Factors and Other Health Problems 14-16.

3. Monnier L, Collete C (2008) Glycemic variability- Should we and can we prevent it? Diabetes care 31I S150-S154.

4. Monnier L, Colette C, Owens D (2008) Glycemic Variability: The Third Component of the Dysglycemia in Diabetes. Is it important? How to Measure it? J Diabetes Sci Technol 2: 1094-1100.

5. Monnier L, Mas E, Ginet C, Michel F, Vilon L, et al. (2006) Activation of oxidative stress by acute glucose fluctuations compared with sustained chronic hyperglycemia in patients with type 2 diabetes. JAMA. 295: 1681-1687.

6. Chon S, Lee YJ, Fraterrigo G, Pozzilli P, Choi MC, et al. (2013) Evaluation of Glycemic Variability in Well Controlled Type 2 Diabetes Mellitus. Diabetes Technol Ther 15: 455-460.

7. Hill NR, Oliver NS, Choudary P, Levy JC, Hindmarsh P, et al. (2011) Norma reference range for mean tissue glucose and glycemic variability derived from continous glucose monitoring for subjects without diabetes in different ethnic groups. Diabetes Technol Ther 13: 921-928.

8. Dupont WD, Plummer WD (1990) Power and Sample Size Calculations: A Review and Computer Program. Controlled Clinical Trials 11: 116-128.

9. Dupont WD, Plummer WD (1998) Power and Sample Size Calculations for Studies Involving Linear Regression', Controlled Clinical Trials 19: 589-601.

10. Fang FS, Li ZB, Li CL, Tian H, Li J, et al. (2012) Influence of Glycemic Variability on HbA1c level in Elderly Male patients with Type 2 Diabetes. Intern Med 51: 3109-3113.

11. Engler B, Koehler C, Hoffman C, Landgraf W, Bilz S, et al. (2011) Relationship between $\mathrm{HbA} 1 \mathrm{c}$ on target, risk of silent hypoglycemia and glycemic variability in patients with type 2 diabetes mellitus. Exp Clin Endocrinol Diabetes 119: 59-61.

12. Su G, Mi S, Tao H, Li Z, Yang HX, et al. (2013) Impact of Admission Glycemic Variability, Glucose and Glycosylated hemoglobin on Major Adverse Cardiac Events after acute myocardial infarct. Diabetes Care 36: 1026-1103.

13. Xu F, Zhao L, Su J, Chen T, Wang X, et al. (2014) The relationship between glycemic variability and diabetic peripheral neuropathy in type 2 diabetes with well controlled HbA1c. Diabetol Metab Syndr 6: 139.

14. Zhou J, Li H, Ran X, Yang W, Li Q, et al. (2011) Establishment of normal reference ranges for glycemic variability in Chinese subjects using continuous glucose monitoring. Med Sci Monit 17: CR9-13.

15. Gribovschi M, Tigan S, Hancu N (2013) Glycemic variability and type 2 diabetes. Appl Med Inform 32: 53-60.

16. Clarke W, Kovatchev B (2009) Statistical tools to analyze continuous glucose monitor data. Diabetes Technol Ther 11: S45-S54.

17. Kovatchev BP, Otto E, Cox D, Gonder-Frederick L, Clarke W (2006) Evaluation of a new measure of blood glucose variability in diabetes. Diabetes Care 29 2433-2438.

18. Hill NR, Hindmarsh PC, Stevens RJ, Stratton IM, Levy JC, et al. (2007) A method for assessing quality of control from glucose profiles. Diabetic Medicine 24: 753-758.

19. Ciccone MM, Aquilino A, Cortese F, Scicchitano P, Sassara M, et al. (2010) Feasibility and effectiveness of a disease and care management model in the primary health care system for patients with heart failure and diabetes (Project Leonardo). Vasc Health Risk Manag 6: 297-305. 